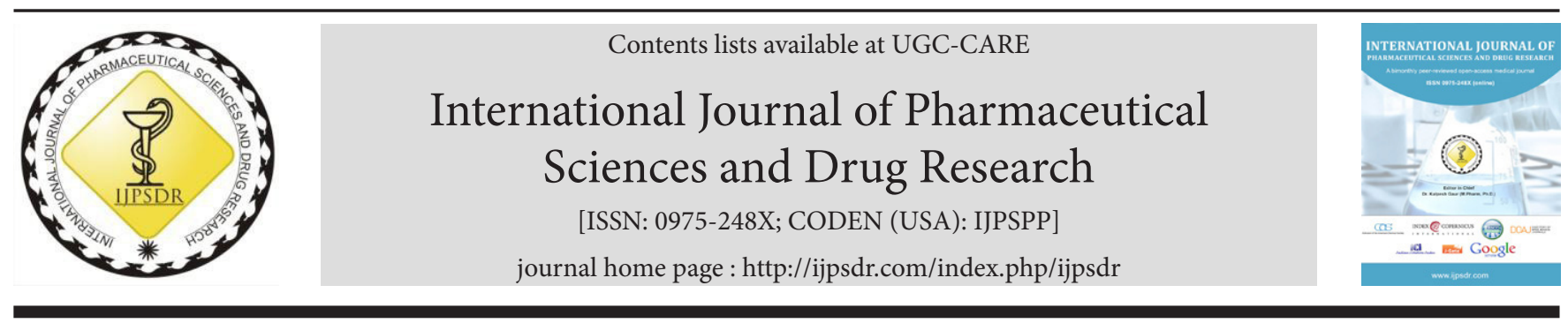

Research Article

\title{
Direct Stereoselective Method Development and Validation of Elagolix on Zwitterionic Chiral Stationary Phase by High-Pressure Liquid Chromatography
}

\author{
Thirupathi Choppari ${ }^{1}$, Srinivasu Gunnam ${ }^{1}$, Lakshmi Narayana Chennuru1, Parameswara Murthy Cherla ${ }^{2}$ \\ ${ }^{1}$ Daicel Chiral Technologies (India) Pvt. Ltd., IKP Knowledge Park, Hyderabad-500078, Telangana, India \\ ${ }^{2}$ Department of Chemistry, Osmania University, Amberpet, Hyderabad-500007, Telangana, India
}

\begin{tabular}{l} 
A R T I C L E I N F O \\
\hline Article history: \\
Received: 25 May, 2020 \\
Revised: 24 July, 2020 \\
Accepted: 20 August, 2020 \\
Published: 30 September, 2020 \\
Keywords: \\
Chiralpak ZWIX(+), \\
Elagolix, Enantiomer, \\
GnRH antagonist, Validation. \\
DOI: \\
10.25004/IJPSDR.2020.120513
\end{tabular}

\section{INTRODUCTION}

Elagolix (ELGX), marketed as Orilissa brand name, is a gonadotropin-releasing hormone (GnRH) antagonist drug, which is utilized to treat pain in premenopausal women accompanying with endometriosis. ${ }^{[1-8]}$ This medicament is also under the development process to treat heavy menstrual bleeding and uterine fibroids in women. ${ }^{[8]}$ Endometriosis develops when tissue that is similar to the kind that is normally located in the uterus starts to grow outside of the uterus. Such growth leads to various symptoms, like pain during periods, pelvic pain between periods, and pain during sexual intercourse. The growths themselves are referred to as lesions and frequently develop on the ovaries, fallopian tubes, and other areas around the uterus, including the bowel or bladder. The growth of these lesions is dependent upon the estrogen hormone. ${ }^{[4-6]}$
ELGX belongs to the class of non-peptide small molecule $\mathrm{GnRH}$ receptor antagonist that binds to $\mathrm{GnRH}$ receptors in the pituitary gland and prevents the endogenous GnRH-signaling. ELGX administration resulting in the dose-dependent suppression of follicle-stimulating hormone (FSH) and luteinizing hormone ( $\mathrm{LH}$ ) leads to a decrease in blood ovarian sex hormones, progesterone, and estradiol concentration levels. IUPAC naming of ELGX is 4-[[(1R)-2-[5-(2-Fluoro-3-methoxyphenyl) -3-[[2- fluoro -6- (trifluoromethyl) phenyl] methyl] -4methyl -2, 6-dioxopyrimidin-1-yl]-1-phenylethyl]amino] butanoic acid (Fig. 1) with molecular mass and formula of 631.590 g.mol$^{-1}$ and $\mathrm{C}_{32} \mathrm{H}_{30} \mathrm{~F}_{5} \mathrm{~N}_{3} \mathrm{O}_{5}$, respectively. It has one chiral center and exhibits two enantiomeric ( $\mathrm{R}$ and S) forms. Among these two, only R-isomer will produce the therapeutic action against the GnRH and useful in endometriosis, and the S-isomer will not produce the

\footnotetext{
*Corresponding Author: Thirupathi Choppari

Address: Associate Director, Daicel Chiral Technologies (India) Pvt. Ltd., IKP Knowledge Park, Hyderabad-500078, Telangana, India

Email $₫$ : thirrudrl@gmail.com, thirupathi@chiral.daicel.com

Relevant conflicts of interest/financial disclosures: The authors declare that the research was conducted in the absence of any commercial or financial relationships that could be construed as a potential conflict of interest.

Copyright (C) 2020 Thirupathi Choppari et al. This is an open access article distributed under the terms of the Creative Commons AttributionNonCommercial-ShareAlike 4.0 International License which allows others to remix, tweak, and build upon the work non-commercially, as long as the author is credited and the new creations are licensed under the identical terms.
} 


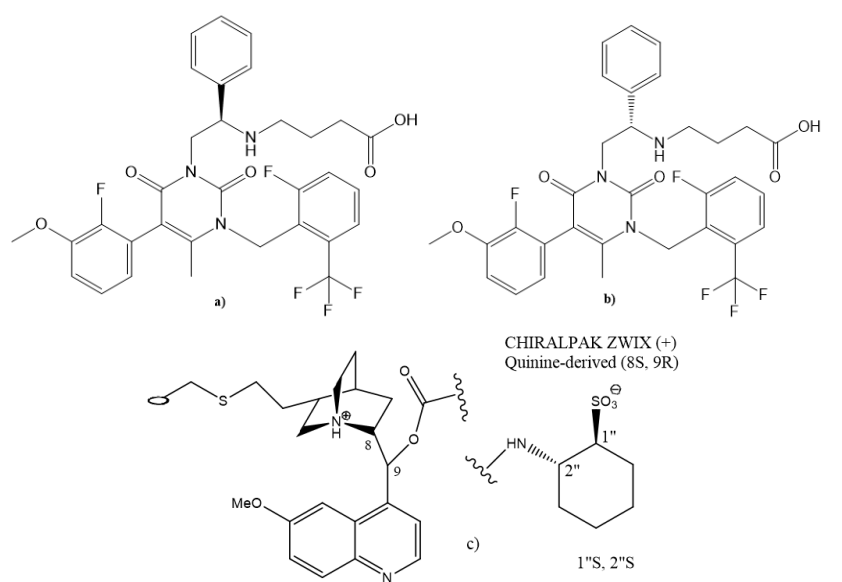

Fig. 1: Chemical structures of ELGX: a) S-isomer (enantiomer); b) R-isomer [Active Pharmaceutical Ingredient (API)]; c) Chiralpak ZWIX chiral stationary phases

same. ${ }^{[9-11]}$ If S-isomer is present in the final bulk or formulation, it will be considered as an enantiomeric impurity. The development of an analytical method for quantitating enantiomers in bulk and finished product is important for pharmaceutical quality.

The literature on ELGX discloses that no single analytical method was reported for the separation, identification, and quantitation of ELGX enantiomers. The present study focused on developing and validating a stereoselective analytical method for the separation and quantitation of ELGX isomers.

\section{Materials AND METHODS}

\section{Chemicals}

ELGX, its enantiomer were received from Daicel Chiral Technologies India Pvt. Ltd., Hyderabad, India. Acetonitrile, ethanol (EtOH), n-hexane, methanol ( $\mathrm{MeOH})$, acetic acid, trifluoroacetic acid (TFA), diethylamine (DEA), and ammonium formate were obtained from Rankem, Thane, India. Ammonia (25\% aqueous ammonia solution) and formic acid were bought from Merck, Mumbai, India. High performance liquid chromatography (HPLC) grade water was made from Milli-Q (Merck) water purification system Molsheim, France.

\section{Instrumentation and Chromatographic Conditions}

The liquid chromatographic (Shimadzu Corporation, Japan) system utilized with ultra violet (UV) detection system consisting of degasser: DGU-20A5, pumps: LC-20AD, column thermostat: CTO-20AC, autosampler: SIL-20A, coupled with photodiode array detector (SPD-M20A), and Valco column switching valve. The columns in use were Chiralpak ZWIX(+) $(250 \times 4 \mathrm{~mm}) 3 \mu$ and Chiralpak QN-AX $(150 \times 4.6 \mathrm{~mm}) 5 \mu$, commercialized by Daicel Corporation (Tokyo, Japan) and manufactured at Chiral Technologies Europe (Illkirch, France). Other polysaccharidederived columns (Chiralpak IA, IB, IC, ID, IE, IF, IG, IH, Chiralpak AD, Chiralpak AS, Chiralpak AY, AZ, CHIRALCEL
OD, OJ, OX, and OZ) took part in the preliminary research, commercialized by Daicel Corporation (Tokyo, Japan).

The composition of optimized mobile phasic system processed on Chiralpak ZWIX $(+)(250 \times 4 \mathrm{~mm} ; 3 \mu)$ column was $50 \mathrm{mM}$ acetic acid and $25 \mathrm{mM}$ DEA in $\mathrm{MeOH}$ and water in the proportion of $90: 2 \% \mathrm{v} / \mathrm{v}$. It was subjected to filtration through a 0.45 -micron membrane filter before utilization. The temperature of the column was monitored at $40^{\circ} \mathrm{C}$ with a $0.5 \mathrm{~mL} \mathrm{~min}^{-1}$ flow rate. The eluted compounds were monitored at $275 \mathrm{~nm}$ with $10 \mu \mathrm{L}$ injection volume and 20 minutes run time. $\mathrm{MeOH}$ of $100 \%$ was utilized as a diluent for the sample processing at the concentration of $0.5 \mathrm{mg} / \mathrm{mL}$ for injection.

\section{Standard Stock Solutions}

Weighed and transferred each $50 \mathrm{mg}$ of ELGX and $\mathrm{S}$-isomers separately into individual $10 \mathrm{~mL}$ volumetric flasks, added $5 \mathrm{~mL}$ diluent, and sonicated to dissolve. Further makeup to volume with diluent and mixed well. The obtained samples' concentration is ELGX (5 mg mL $\left.\mathrm{m}^{-1}\right)$ and enantiomer $\left(5 \mathrm{mg} \mathrm{mL}^{-1}\right)$ stock solutions.

\section{Sample Preparation}

Weighed and transferred $50 \mathrm{mg}$ of ELGX into $10 \mathrm{~mL}$ volumetric flasks, added $5 \mathrm{~mL}$ diluent, and sonicated to dissolve. Further, make up to volume with diluent and mixed well. Serial dilutions were made to obtain a working sample solution of a concentration of $0.5 \mathrm{mg} \mathrm{mL}^{-1}$.

\section{Analytical Method Validation}

The developed method was subjected to validation in the present research work as per the ICH $Q_{2}\left(R_{1}\right)$ guidelines. Validation was executed for the parameter's specificity, accuracy, linearity, robustness, linearity, the limit of detection (LOD), the limit of quantification (LOQ), and precision. ${ }^{[12-16]}$

\section{Specificity}

The analytical method specificity and selectivity were evaluated by infusing ELGX spiked with its isomer and its precursor at a $0.15 \%$ concentration level with respect to $0.5 \mathrm{mg} \mathrm{mL}^{-1}$ sample concentration.

\section{Precision}

Precision was processed in terms of system precision and method precision. System precision was processed by infusing six individual standard preparations of ELGX spiked at $100 \%$ level with respective to $0.5 \mathrm{mg} \mathrm{mL}^{-1}$ analyte concentration. Method precision was processed by infusing both sample and standard spiked samples. The $\%$ relative standard deviation (\% RSD) was estimated for enantiomer in the spiked and test preparation.

\section{Limit of Quantification (LOQ) and Limit of Detection (LOD)}

LOQ and LOD for ELGX enantiomers were assessed by signalto-noise $(\mathrm{S} / \mathrm{N})$ ratios of 10:1 and 3:1, respectively, by infusing 
a series of dilute solutions with known concentrations. The LOQ precision was executed by infusing six individual preparations, and the \% RSD values were estimated for the peak responses of ELGX enantiomers.

\section{Linearity}

Method linearity is its capacity to get test outcomes, which are directly proportional to the drug concentration in the sample. Linearity solutions were processed by serial dilution of the stock solutions of enantiomers to a required concentration. Enantiomers solutions were processed at six different levels of concentration from LOQ level to $150 \%$ with respect to the enantiomer specification level of $0.15 \%$. The linearity curves for the enantiomers were plotted by taking peak response on the Y-axis and respective concentrations on X-axis. The values of intercept, slope, and correlation coefficient of the linearity graph were assessed.

\section{Accuracy}

The closeness of agreement between true or reference value and the measured value expresses the accuracy of the analytical method. The recovery studies were processed to estimate the accuracy of the analytical liquid chromatographic technique for the quantitation of potential enantiomeric impurity of ELGX in drug samples. The experiment was executed in triplicate at three different concentration levels, i.e., 50, 100, and 150\%, with respect to $0.5 \mathrm{mg} \mathrm{mL}^{-1}$ sample concentration.

\section{Robustness}

To estimate the developed analytical method's robustness, the LC-method conditions were purposely varied. A solution of ELGX drug spiked with its enantiomer at specification level (0.15\%) was used in this study and analyzed six times at each experimental condition. The mobile phase flow of $0.5 \mathrm{~mL} / \mathrm{min}$ to assess the effect of flow change on the resolution, varied to 0.45 and $0.55 \mathrm{~mL} / \mathrm{min}$. To assess the effect of variation in movable phase proportion of water varied to 5 and $10 \%$ level. The optimized column oven temperature (COT) of $25^{\circ} \mathrm{C}$, also varied to 15 and $40^{\circ} \mathrm{C}$.

\section{RESULTS AND DISCUSSION}

\section{Preliminary Screening for Column Selection}

In the present research work on the elution of ELGX enantiomers, different CSPs had been trialed with, together with polysaccharide-derived CSPs under polar, reverse, and normal phases with dual additives due to the amphoteric nature of the molecule. QN-AX-based CSPs, as well as, the cinchona-based CSPs under reverse phase. Preliminary screenings mainly focus on (i) selection of chiral column, (ii) role and strength of additives in the resolution of enantiomer, and (iii) optimization on the separation of enantiomers.

\section{Selection of Chiral Column}

A systematic screening study was executed on the immobilized and coated amylose, and cellulose derived CSPs (Fig. 2) in polar, normal, and reversed-phase modes. $[17,18]$ In polar mode with $\mathrm{MeOH} / \mathrm{DEA} / \mathrm{TFA}(100 / 0.1 / 0.1$ $\% \mathrm{v} / \mathrm{v} / \mathrm{v}$ ) and $\mathrm{MeOH} /$ acetonitrile/DEA/TFA (50/50/0.1/0.1 $\% \mathrm{v} / \mathrm{v} / \mathrm{v} / \mathrm{v}$ ) as mobile phases, there was no enantiomeric selectivity observed. In normal phase with n-hexane/EtOH/ TFA/DEA (70/30/0.1/0.1 v/v/v/v) and n-hexane/IPA/TFA/ DEA (70/30/0.1/0.1 v/v/v/v), partial separations with peak broadening on Chiralpak IC, Chiralpak IG, Chiralpak AD-H, and CHIRALCEL OX-H polysaccharide-derived CSPs, and no selectivity with peak broadening on rest of the columns. In the reverse phase mode, the chromatographic system was processed with two programs consisting of solvent A (10 mM ammonium bicarbonate) and solvent B (100\% acetonitrile in one program and $100 \%$ methanol in another program). The gradient elution was monitored as time/B\%, i.e., 0/10, 10/80, 15/80, 15.1/10, 20/10, at $1 \mathrm{~mL} / \mathrm{min}$. The separation of an enantiomer, as well as, rotamers were separated on CHIRALCEL OX-3R, in which drug product rotamer has been co-eluting at enantiomer retention time under both gradient programs and not possible for the quantification of enantiomer in analyte due to co-elution of rotamers.

ELGX has amphoteric in nature, so the Chiralpak ZWIX(Fig. 1c) column is the best choice for stereoselectivity. To suppress the intra-molecular counter ion effect of the selector, basic and acidic additives were utilized, like DEA, and formic acid or diethylamine was suggested to moderate the pairing of ions and ion-exchange mechanisms between the selectors.

Baseline separation was achieved in the primary screening mobile phase as $25 \mathrm{mM} \mathrm{HCOOH}$ and $25 \mathrm{~mm}$ ammonium formate $(\mathrm{MeOH} /$ water $90 / 10$ $\% \mathrm{v} / \mathrm{v}$ ); baseline separation was observed with partial rotamers separation. Favorable elution was noticed on Chiralpak ZWIX(+) column, and the same was chosen for optimization.

\section{Role and Strength of Additives in Resolution of Enantiomers}

As per the literature on ZWIX columns, ${ }^{[19-21]} \mathrm{MeOH}$ was an important solvent system in the mobile phase composition. The addition of fewer proportions of water content was favorable for moderating, retaining, and improving the solubility of analytes in the mobile phase. Owing to the intra-molecular counter ion consequence of the chiral selectors, utilization of basic and acidic additives, like acetic acid, ammonium formate, DEA, and formic acid, is suggested to moderate the ion-pairing and ion-exchange mechanisms between the selector and the analyte molecules. In addition to the mobile phase composition, it was necessary to consider the detection viability and sensibility of the separation method. Further 


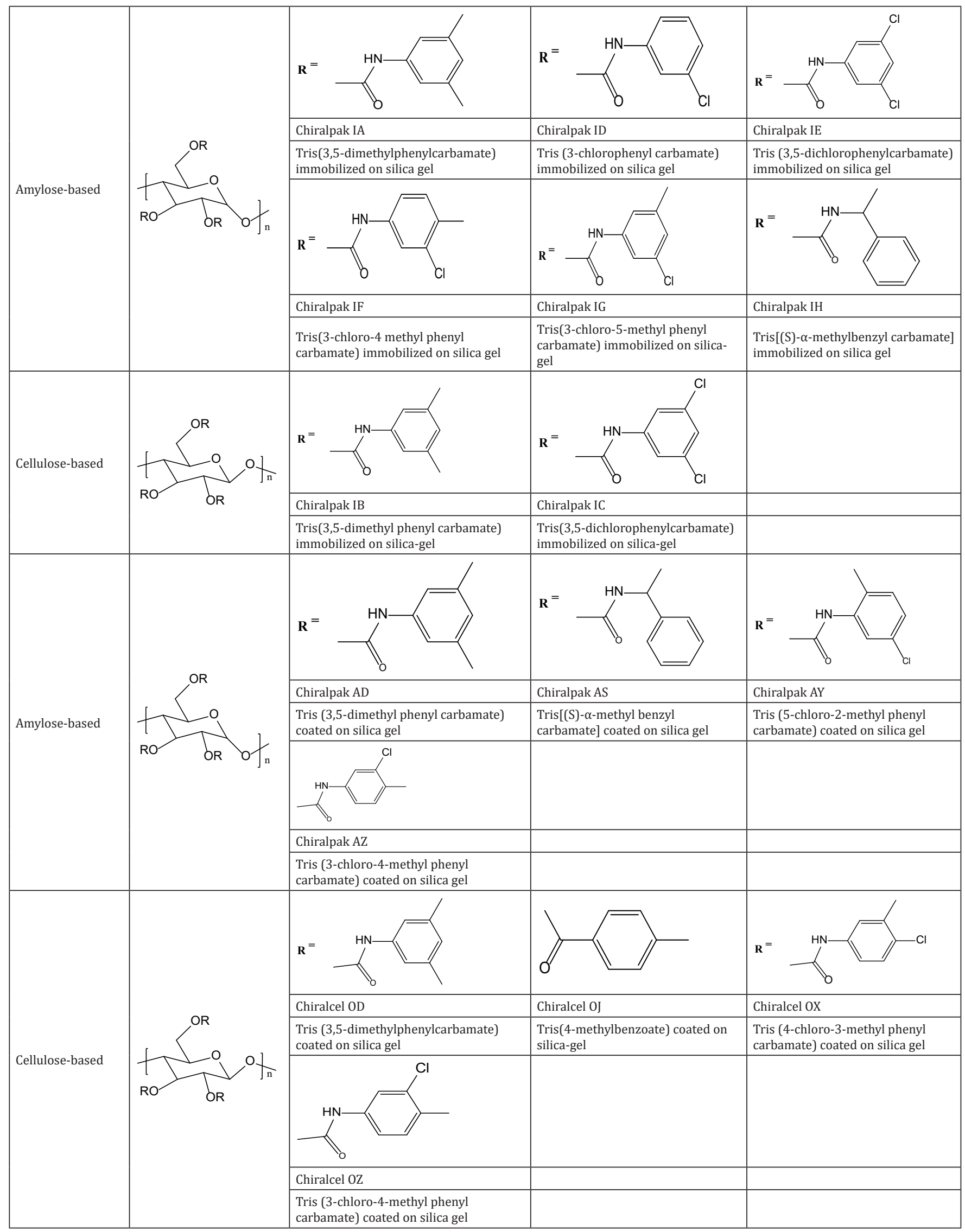

Fig. 2: Types of polysaccharide-based chiral stationary phases 
investigations were conducted by changing the additive strength and composition of acid-bases. Better efficiency parameters were produced by the additive combination of $50 \mathrm{mM}$ acetic acid $+25 \mathrm{mM}$ diethylamine.

Baseline separation and the good resolution were obtained with Chiralpak ZWIX CSPs, with a reversed separation order detected between the ZWIX(-) and ZWIX(+) CSPs, which contain, respectively, the zwitterionic chiral selectors behaving as pseudo-enantiomers. ${ }^{[19,20]}$ Due to the encouraging elution order (minor enantiomers separated initially) found on the Chiralpak ZWIX(+) stationary phase, such a column was elected for further examination.

\section{Optimization of Temperature}

Temperature plays a vital role in the separation of enantiomers by utilizing CSPs. In most cases, the impurity peaks will co-elute with the enantiomers with lowresolution efficiency. In the present work, the optimized chromatographic parameters were subjected to variation in column oven temperature and processed at $40^{\circ} \mathrm{C}$ (Fig. 3a), and $25^{\circ} \mathrm{C}$ (Fig $3 \mathrm{~b}$ ). The resulting overlaid chromatograms were shown in Fig. 3 . At $25^{\circ} \mathrm{C}$, the impurity peaks were eluting by merging with the enantiomeric peaks, compared with the chromatogram at $40^{\circ} \mathrm{C}$ temperature, $3 \mathrm{a}$ and $3 \mathrm{~b}$ present in Fig. 3 overlaid. At $40^{\circ} \mathrm{C}$, unknown impurities were well resolved, and no interference with enantiomeric peak

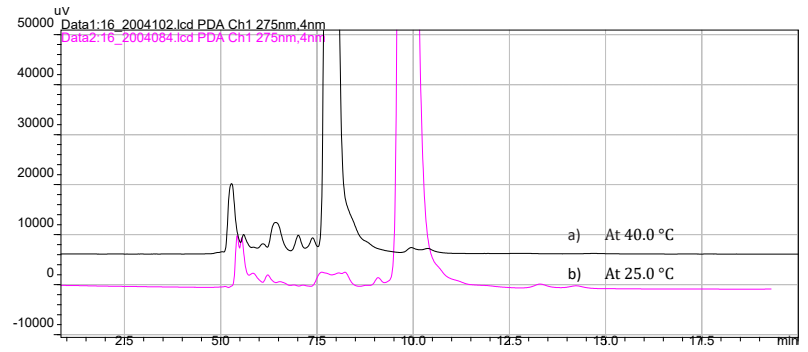

Fig. 3: Effect of temperature on chromatographic separation of enantiomers [3(a) at $40^{\circ} \mathrm{C}$ and $3(\mathrm{~b})$ at $\left.25^{\circ} \mathrm{C}\right]$

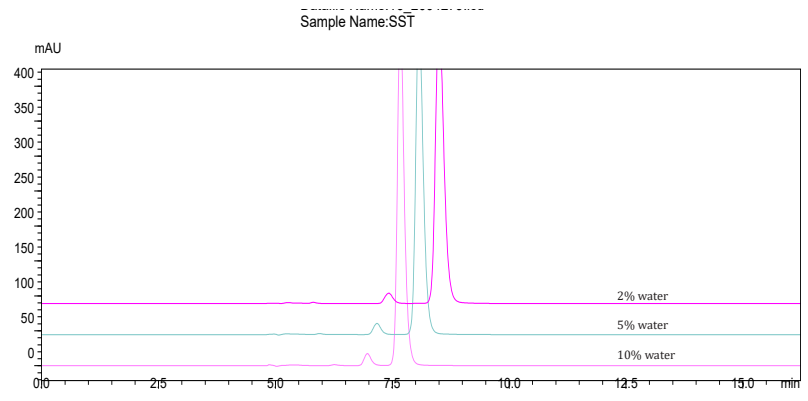

Fig. 4: Effect of water ratio in mobile phase on chromatographic separation of enantiomers and no loss of resolution and was selected as optimized temperature.

\section{Optimization of Water Ratio in Mobile Phase}

Water ratio in the mobile phase composition also alters the resolution, retention time, and total run time of chromatogram. To optimize the water ratio in the mobile phase, the study was further investigated at variation in water ratio at 2, 5, and 10\% levels. Among three levels, at $2 \%$ water level, the finest resolution was observed and optimized (Fig. 4).

\section{Validation}

\section{Specificity and Selectivity}

The method specificity and selectivity of the developed chiral method were assessed in the presence of its enantiomer from products. Peak purity and the threshold were calculated and represented in Table 1, and Figs 5 and 6 , and were within the limit.

\section{Linearity}

The linearity of the present technique was estimated in a concentration range from LOQ to $150 \%$ with respect to analyte concentration at $0.5 \mathrm{mg} \mathrm{mL}^{-1}$ for the enantiomers by processing six standard solutions. The values of intercept, slope, and correlation coefficient of the linearity graph were reported and represented in Table 2, and Figs. 7 and 8.

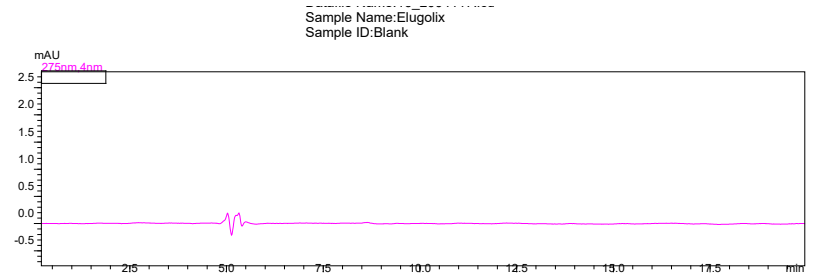

Fig. 5: Representative chromatogram of ELGX blank

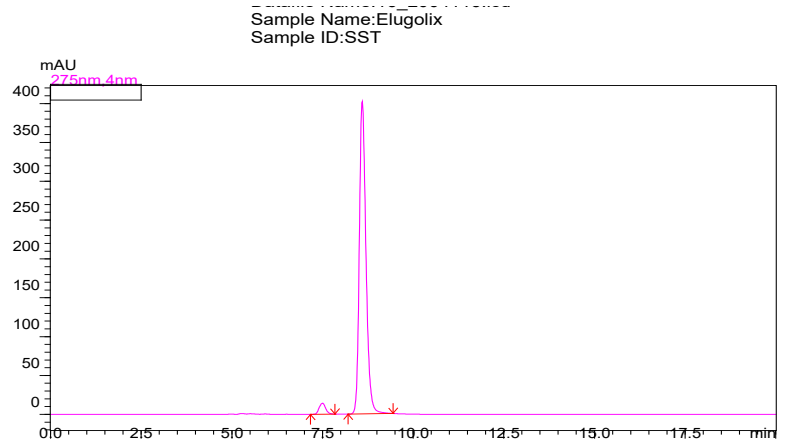

Fig. 6: Representative chromatogram of ELGX spiked sample at $100 \%$ level

Table 1: Peak purity of ELGX and its enantiomer

\begin{tabular}{llll}
\hline Spiked sample result & RT (min) & Purity factor & Threshold \\
\hline ELGX enantiomer & 8.46 & 999.99 & 999.625 \\
ELGX API & 9.702 & 999.987 & 999.245 \\
\hline
\end{tabular}

RT: Retention time 
Thirupathi Choppari et al.

Table 2: Linearity of ELGX enantiomers

\begin{tabular}{|c|c|c|c|c|}
\hline \multirow{2}{*}{$\begin{array}{l}\text { Concentration } \\
\text { level }\end{array}$} & \multicolumn{2}{|l|}{ ELGX API } & \multicolumn{2}{|l|}{ ELGX enantiomer } \\
\hline & Conc. in $\mu \mathrm{g} / \mathrm{mL}$ & Average area $^{a}$ & Conc. in $\mu g / m L$ & Average area $^{a}$ \\
\hline LOQ & 0.0075 & 948 & 0.0075 & 843 \\
\hline $50 \%$ & 0.0748 & $8,170.5$ & 0.0786 & 7,805 \\
\hline $75 \%$ & 0.1122 & $12,255.75$ & 0.1179 & $12,557.5$ \\
\hline $100 \%$ & 0.1496 & $17,325.5$ & 0.1571 & $17,413.5$ \\
\hline $125 \%$ & 0.187 & $21,656.875$ & 0.1963 & $21,766.88$ \\
\hline $150 \%$ & 0.2244 & 26,772 & 0.2357 & $26,113.5$ \\
\hline $\mathrm{CC}$ & 0.9993 & & 0.9991 & \\
\hline Intercept & $1,497.1$ & & 113,782 & \\
\hline Slope & 125,145 & & 684.18 & \\
\hline
\end{tabular}

CC: Correlation coefficient; ${ }^{\text {a: }}$ Two injections

Table 3: System precision data of ELGX enantiomer

\begin{tabular}{ll}
\hline S. No. & Peak area of ELGX enantiomer \\
\hline 1 & $12,237,348$ \\
2 & $12,222,142$ \\
3 & $12,223,425$ \\
4 & $12,212,120$ \\
5 & $12,200,196$ \\
6 & $12,188,579$ \\
Average & $12,213,968.3$ \\
Standard deviation & $17,553.10761$ \\
$\%$ RSD & 0.143713387 \\
\hline
\end{tabular}

RSD: Relative standard deviation

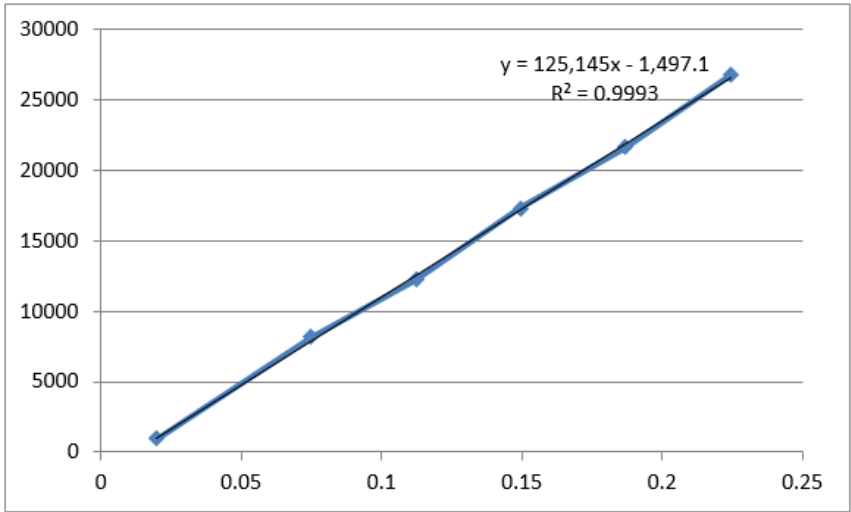

Fig. 7: Linearity of ELGX API

Limit of Detection (LOD) and Limit of Quantification (LOQ)

LOD and LOQ were assessed as the concentration of the analyte, giving rise to an $\mathrm{S} / \mathrm{N}$ ratio of 3 and 10 , respectively. The LOD/LOQ values of ELGX enantiomer were found to be 2 and $7.5 \mathrm{ng} \mathrm{mL}^{-1}$, respectively (Figs 9 and 10). The findings of the technique prove the sensitivity of the proposed method for the quantification of ELGX enantiomer.

\section{Precision}

The precision of the analytical procedure was assessed in terms of system and method precision. The $\%$ RSD values
Table 4: Method precision data of ELGX enantiomer

\begin{tabular}{ll}
\hline Sample name & Enantiomeric impurity in $\mu \mathrm{g} / \mathrm{mL}$ \\
\hline Method precision-1 & 0.146 \\
Method precision-2 & 0.149 \\
Method precision-3 & 0.152 \\
Method precision-4 & 0.147 \\
Method precision-5 & 0.154 \\
Method precision-6 & 0.14 \\
Average & 0.148 \\
Standard deviation & 0.005 \\
\% RSD & 3.32 \\
\hline
\end{tabular}

RSD: Relative standard deviation

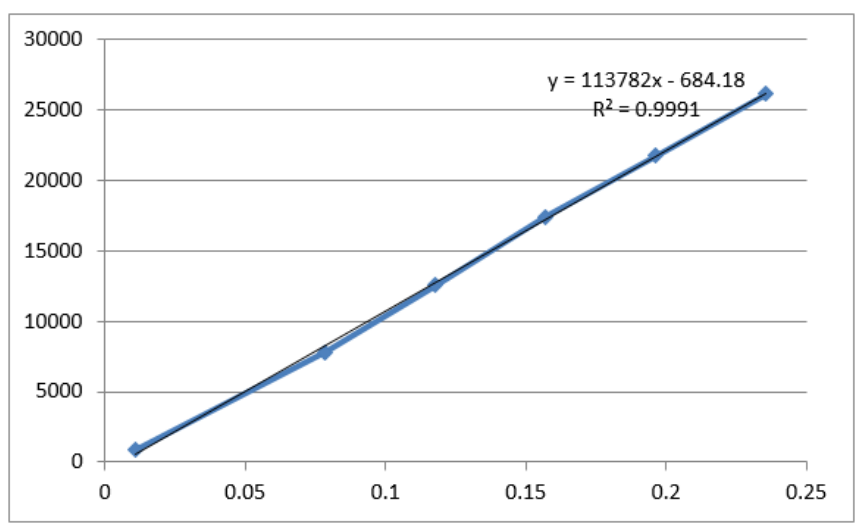

Fig. 8: Linearity of ELGX enantiomer

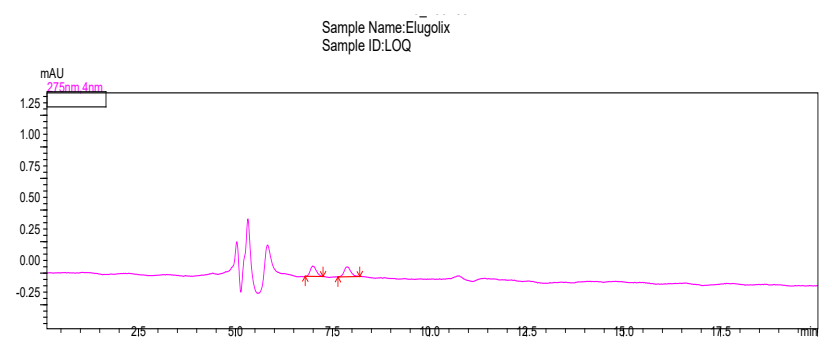

Fig. 9: Representative chromatogram at LOQ level

for system and method precision were found to be 0.14 and 3.32. The findings are shown in Tables 3 and 4. 
Stereoselective Separation of Elagolix by Zwitterionic CSP-HPLC

Table 5: Accuracy data of ELGX enantiomer

\begin{tabular}{|c|c|c|c|c|c|c|c|}
\hline \multirow{2}{*}{ Sample name } & & \multicolumn{6}{|c|}{ ELGX enantiomer } \\
\hline & & \multicolumn{2}{|c|}{ Spiked conc. in $\mu \mathrm{g} / \mathrm{mL}$} & \multicolumn{2}{|c|}{ Measured conc. in $\mu \mathrm{g} / \mathrm{mL}$} & \multicolumn{2}{|c|}{$\%$ recovery } \\
\hline \multicolumn{2}{|l|}{ Accuracy 50\%-1 } & \multicolumn{2}{|c|}{0.076} & \multicolumn{2}{|c|}{0.086} & \multicolumn{2}{|c|}{113.2} \\
\hline \multicolumn{2}{|l|}{ Accuracy $50 \%-2$} & \multicolumn{2}{|l|}{0.076} & \multicolumn{2}{|l|}{0.083} & \multicolumn{2}{|c|}{101.3} \\
\hline \multicolumn{2}{|l|}{ Accuracy $50 \%-3$} & \multicolumn{2}{|l|}{0.076} & \multicolumn{2}{|l|}{0.083} & \multicolumn{2}{|c|}{101.3} \\
\hline \multicolumn{2}{|l|}{ Accuracy $100 \%-1$} & \multicolumn{2}{|l|}{0.151} & \multicolumn{2}{|l|}{0.147} & \multicolumn{2}{|l|}{93.4} \\
\hline \multicolumn{2}{|l|}{ Accuracy $100 \%-2$} & \multicolumn{2}{|l|}{0.151} & \multicolumn{2}{|l|}{0.149} & \multicolumn{2}{|l|}{94.7} \\
\hline \multicolumn{2}{|l|}{ Accuracy $100 \%-3$} & \multicolumn{2}{|l|}{0.151} & \multicolumn{2}{|l|}{0.15} & \multicolumn{2}{|l|}{95.4} \\
\hline \multicolumn{2}{|l|}{ Accuracy $150 \%-1$} & \multicolumn{2}{|l|}{0.227} & \multicolumn{2}{|l|}{0.245} & \multicolumn{2}{|c|}{105.3} \\
\hline \multicolumn{2}{|l|}{ Accuracy $150 \%-2$} & 0.227 & & 0.24 & & 103. & \\
\hline Accuracy $150 \%-3$ & & 0.227 & & 0.253 & & $108 . \varepsilon$ & \\
\hline & & Tabl & : Robustne & ta of ELGY & mers & & \\
\hline & & & & & matograph & ncy & \\
\hline Variation in parameter & & & $t_{1}$ & $t_{2}$ & $R_{s}$ & $N_{1}$ & $N_{2}$ \\
\hline & $15^{\circ} \mathrm{C}$ & & 0.963 & 1.374 & 4.059 & 3,578 & 5,245 \\
\hline & $25^{\circ} \mathrm{C}$ & & 0.966 & 1.263 & 3.816 & 4,990 & 7,112 \\
\hline Temperature & $40^{\circ} \mathrm{C}$ & & 1.104 & 1.259 & 3.203 & 8,184 & 9,941 \\
\hline & 0.45 & & 1.121 & 1.251 & 3.265 & 8,411 & 10,396 \\
\hline Flow rate & 0.5 & & 1.097 & 1.258 & 3.205 & 8,317 & 9,888 \\
\hline$(\mathrm{mL} / \mathrm{min})$ & 0.55 & & 1.132 & 1.259 & 3.096 & 7,705 & 9,398 \\
\hline & $2 \%$ & & 1.114 & 1.01 & 3.2 & 7,981 & 10,043 \\
\hline & $5 \%$ & & 1.201 & 1.21 & 2.9 & 8,641 & 11,178 \\
\hline$\%$ water & $10 \%$ & & 1.101 & 1.014 & 2.5 & 9,418 & 12,412 \\
\hline
\end{tabular}

$\mathrm{R}_{\mathrm{s}}$ : Resolution; N: Theoretical plates; t: Tailing factor

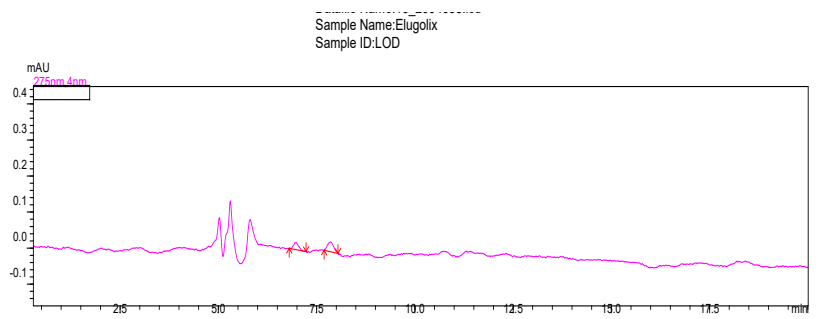

Fig. 10: Representative chromatogram at LOD level

Accuracy

Method accuracy was processed, evaluated, and the respective results were shown in Table 5. The percentage recoveries of the enantiomer were found between 93.4 to $113.2 \%$. The findings of the accuracy data concluded that the developed analytical method was accurate.

\section{Robustness}

The method robustness was processed and evaluated for resolution and \% RSD by varying the optimized chromatographic conditions, like mobile phase composition, flow rate, and COT. The resolution between isomers was more than two, and the \% RSD values were found between 2 to 2.7. The chromatographic efficiency results are shown in Table 6.

\section{CONCLUSION}

A specific, sensitive, and accurate stereo selective chiral technique has been developed for the quantification of ELGX enantiomer in drug products and drug substances by chiral HPLC. The enantiomers were eluted on a CSP comprising a zwitterionic selector derived from cinchona alkaloid and sulfonic acid [Chiralpak ZWIX(+)] under isocratic condition containing $50 \mathrm{mM}$ acetic acid and $25 \mathrm{mM}$ diethylamine in water and methanol in the ratio of $2: 98 \mathrm{v} / \mathrm{v}$ with a flow rate $0.5 \mathrm{~mL} \mathrm{~min}^{-1}$ at the column oven temperature $40^{\circ} \mathrm{C}$ with a resolution factor more than 3.2. The eluted compounds were monitored at $275 \mathrm{~nm}$. The percentage recoveries of the enantiomer were found between 93.4 to $113.2 \%$. The method was found to be stereoselective with LOD and LOQ values of 2 and $7.5 \mathrm{ng} / \mathrm{mL}$, respectively. The validated method can be successfully applied in routine analysis of ELGX enantiomers in bulk and formulations by pharmaceutical organizations.

\section{ACKNOWLEDGMENTS}

The authors thank the management of Daicel Chiral Technologies, India, for supporting this work. 


\section{REFERENCES}

1. Tukun FL, Olberg DE, Riss PJ, Haraldsen I, Kaass A, Klaveness J. Recent development of non-peptide GnRH antagonists, molecules. 2017;22(12):188.

2. Struthers RS, Nicholls AJ, Grundy J, Chen T, Jimenez R, Yen SS, Bozigian HP. Suppression of gonadotropins and estradiol in premenopausal women by oral administration of the nonpeptide gonadotropin-releasing hormone antagonist elagolix, J. Clin. Endocrinol. Metab. 2009;94(2):545-551.

3. Ezzati Mohammad, Carr Bruce R. Elagolix, a novel, orally bioavailable GnRH antagonist under investigation for the treatment of endometriosis-related pain. Women's Health. 2015;11(1): 19-28.

4. Orilissa (elagolix) Health Canada Product MonograpH (PDF). 4 October 2018. Retrieved 15 February 2019.

5. Lamb YN. Elagolix: First Global Approval. Drugs. 2018;78(14):15011508.

6. Clemenza S, Sorbi F, Noci I, Capezzuoli T, Turrini I, Carriero C, Buffi N, Fambrini M, Petraglia F. From pathogenesis to clinical practice: Emerging medical treatments for endometriosis. Best Pract Res Clin Obstet Gynaecol. 2018;51:92-101.

7. Melis GB, Neri M, Corda V, Malune ME, Piras B, Pirarba S, et al. Overview of elagolix for the treatment of endometriosis. Expert Opin Drug Metab Toxicol. 2016; 12(5):581-588.

8. Giudice LC. Clinical practice, endometriosis. N Engl J Med. 2010; 362(25): 2389-2398.

9. Nnoaham KE, Hummelshoj L, Webster P, d'Hooghe T, de Cicco Nardone F, de Cicco Nardone C, et al. Impact of endometriosis on quality of life and work productivity: a multicenter study across ten countries. Fertil Steril. 2011; 96(2);366-373.

10. ICH Q2 (R1); Validation of Analytical Procedures: Text and Methodology; (2005).

11. Tong Z, Dung N, Pilar F. Development and validation of the chiral HPLC method for daclatasvir in gradient elution mode on amylosebased immobilized chiral stationary phase. J Chromatogr. A. 2008;
1191:214-222.

12. Morante-Zarcero S, Sierra I. Comparative HPLC methods for $\beta$-blockers separation using different types of chiral stationary phases in normal phase and polar organic phase elution modes. Analysis of propranolol enantiomers in natural waters. J Pharm Biomed Anal. 2012;62:33-41.

13. Rahman A, Haque MR, Sultan MZ, Rahman MM, Rashid MA. Enantiomeric Determination of Carvedilol by a Newly Developed and Validated Chiral HPLC Method. Dhaka University Journal of Pharmaceutical Sciences. 2019 May 16;18(1):61-68.

14. Kunath A, Theil F, Jähnisch K. Influence of the kind of the alcoholic modifier on chiral separation on a Chiralpak AD column. Journal of Chromatography A. 1996;728(1-2):249-257.

15. Jin JY, Bae SK, Lee W. Comparative studies between covalently immobilized and coated chiral stationary phases based on polysaccharide derivatives for enantiomer separation of $N$-protected $\alpha$-amino acids and their ester derivatives. Chirality. 2009;21(10):871-877.

16. Toussaint B, Duchateau, Vanderwal S, Albert A, Hubert P, Crommen J. Determination of the enantiomers of 3-tertbutylamino-1,2propanediol by high performance liquid chromatography coupled to evaporative light scattering detection. J Chromatogr. A. 2000; 890(2):239-249.

17. Hoffmann CV, Pell R, Lämmerhofer M, Lindner W. Synergistic effects on enantioselectivity of zwitterionic chiral stationary phases for separations of chiral acids, bases, and amino acids by HPLC, Anal. Chem. 2008;80:8780-8789.

18. Zhang T, Holder E, Franco P, Lindner W. Zwitterionic chiral stationary phases based on cinchona and chiral sulfonic acids for the direct stereoselective separation of amino acids and other amphoteric compounds. J. Sep. Sci. 2014;37(11):1237-1247.

19. Zhang T, Holder E, Franco P, Lindner W. Method development and optimization on cinchona and chiral sulfonic acid-based zwitterionic stationary phases for enantiomer separations of amino acids by high-performance liquid chromatography. J. Chromatogr. A. 2014;1363:191-199.

HOW TO CITE THIS ARTICLE: Choppari T, Gunnam S, Chennuru LN, Murthy CP. Direct stereoselective method development and validation of elagolix on zwitterionic chiral stationary phase by high-pressure liquid chromatography. Int. J. Pharm. Sci. Drug Res. 2020;12(5):517-524. D0I: 10.25004/ IJPSDR.2020.120513 